\title{
Surgical and Molecular Evaluation of Pediatric Hydatid Cyst Cases in Eastern Turkey
}

\author{
Unal Bakal', Sami Simsek ${ }^{2 *}$, Ahmet Kazez ${ }^{1}$ \\ ${ }^{1}$ Department of Pediatric Surgery, Faculty of Medicine, University of Firat, Elazlğ, Turkey; ${ }^{2}$ Department of Parasitology, Faculty of Veterinary Medicine, \\ University of Firat, Elazlğ, Turkey
}

\begin{abstract}
Cystic echinococcosis (CE) caused by Echinococcus granulosus is a major public health problem worldwide, including Turkey. The aim of the current study was to identify the strains and to estimate the potential risk factors of $E$. granulosus in operated pediatric cases in eastern Turkey. Ten pediatric patients (7 boys and 3 girls) living in rural areas, with ages ranging from 3 to 15 years old and various clinical histories, were included in this study. Eight patients had only liver hydatid cyst, while 1 patient had liver and lung hydatid cyst and the other liver, lung, and spleen, together. There were 2 ruptured liver cysts. After surgery, during follow-up, no increase was observed in hemagglutination levels, there were no mortalities, and there was no evidence of recurrence at 2 years post operation in all patients. Molecular analysis was performed on hydatid cyst samples obtained from the 10 pediatric cases. According to mt-12S rRNA PCR results, all cases were found to be G1/G3 cluster of $E$. granulosus sensu stricto.
\end{abstract}

Key words: Hydatid cyst, pediatric surgery, risk factor, PCR, Turkey

Cystic echinococcosis (CE) is a zoonotic infection caused by the larval (metacestode) stages of cestodes belonging to the genus Echinococcus and the family Taeniidae (1). Infection with eggs of the adult parasite results in the development of 1 or several unilocular hydatid cysts in humans developing mainly in the liver (70\%) but also in the lungs (20\%) and other organs (10\%) (2). Humans act as accidental intermediate host and become infected through contaminated food, water, and feces of dogs containing the eggs (3). Although this infection is seen at all ages, younger individuals are more susceptible to the infection while the gender seems to play no role in the infection (4).

Several factors including cultural, educational, socioeconomical, agricultural, and environmental conditions contribute to the transmission of infection in Turkey (5). Genotyping of human CE cases play an important role in the control strategies for the prevention of the infection.

There are several reports about $E$. granulosus strains circulating in Turkey. E. granulosus sensu stricto (G1-G3 complex), E. canadensis (G6 and G7 genotypes), and E. equinus (G4) have

\footnotetext{
- Received 14 July 2015, revised 21 August 2015, accepted 6 October 2015.

*Corresponding author (ssimsek@firat.edu.tr)

(C) 2015, Korean Society for Parasitology and Tropical Medicine

This is an Open Access article distributed under the terms of the Creative Commons Attribution Non-Commercial License (http://creativecommons.org/licenses/by-nc/3.0) which permits unrestricted non-commercial use, distribution, and reproduction in any medium, provided the original work is properly cited.
}

been reported both in livestock and humans (6-9).

The present study is the first to identify the species/strains of CE present in Turkish young patients who had been surgically confirmed as having CE as well as evaluate some risk factors.

Ten pediatric patients, ages ranging from 3 to 15 years old, with various complaints that admitted to Department of Pediatric Surgery Clinic of the Firat University Hospital between 2011 and 2013 were included in this study. The cases, whose cyst hydatid hemagglutination tests were positive, were diagnosed with US and $\mathrm{CT}$, and diagnoses were confirmed by the surgery. The patients were given albendazole $(10 \mathrm{mg} / \mathrm{kg} /$ day $)$ during 1 week before surgery. Due to liver hydatid cysts, 8 patients underwent right subcostal incision surgery. The patient who was treated with right pulmonary hydatid cyst underwent right thoracotomy and the other one with ruptured spleen hydatid cyst underwent midline incision. The cysts were first taken safely with compresses with $3 \%$ diluted $\mathrm{NaCl}$ and then aspirated with 18G needle, $3 \% \mathrm{NaCl}$ was replaced with taken fluid and inactivation was performed about $10 \mathrm{~min}$. Cystotomy and drainage were performed and then cysts' germinal membranes were removed and cleaned again with $3 \% \mathrm{NaCl}$. Fistulas in patients with bile leakage were closed with $3 / 0$ polydioxanone. The operations were finished by capitonnage process with 2/0 polyglactin to cysts edge and placing drains into cysts. Six to 9 cycles of postoperative albendazole treatment were given and 1-year follow-up was performed. In order to determine 
Table 1. The demographic characteristics and some risk factors of the CE patients

\begin{tabular}{|c|c|c|c|c|c|c|c|c|}
\hline Patient No. & Age & Sex & Origin & Cyst localization & Treatment & Serology & Strain & Risk factors \\
\hline 1 & 7 & Male & Mus & $\begin{array}{l}\text { Ruptured Liver HC+ } \\
\text { Lung } \mathrm{HC}\end{array}$ & $\begin{array}{l}\text { Liver cystotomy/ } \\
\text { cystectomy }\end{array}$ & 1/160 (+) & E.g. sensu stricto & $\begin{array}{l}\text { Hygiene conditions (poor) } \\
\text { Contact with dog (No) }\end{array}$ \\
\hline 2 & 15 & Male & Mus & Liver HC & $\begin{array}{l}\text { Liver cystotomy/ } \\
\text { cystectomy }\end{array}$ & $1 / 320(+)$ & E.g. sensu stricto & $\begin{array}{l}\text { Hygiene conditions (poor) } \\
\text { Contact with dog (Yes) }\end{array}$ \\
\hline 3 & 11 & Male & Bingol & Ruptured Liver HC & $\begin{array}{l}\text { Liver cystotomy/ } \\
\text { cystectomy }\end{array}$ & $1 / 320(+)$ & E.g. sensu stricto & $\begin{array}{l}\text { Hygiene conditions (poor) } \\
\text { Contact with dog (Yes) }\end{array}$ \\
\hline 4 & 11 & Female & Bingol & Liver HC & $\begin{array}{l}\text { Liver cystotomy/ } \\
\text { cystectomy/ } \\
\text { Sphincterotomy }\end{array}$ & $1 / 160(+)$ & E.g. sensu stricto & $\begin{array}{l}\text { Hygiene conditions (poor) } \\
\text { Contact with dog (Yes) }\end{array}$ \\
\hline 5 & 9 & Male & Elazig & $\begin{array}{l}\text { Liver+Lung+ } \\
\text { Spleen HC }\end{array}$ & $\begin{array}{l}\text { Spleen excised one year } \\
\text { ago due to hydatid cyst/ } \\
\text { Thoracotomy and cyst excision }\end{array}$ & $1 / 320(+)$ & E.g. sensu stricto & $\begin{array}{l}\text { Hygiene conditions (poor) } \\
\text { Contact with dog (Yes) }\end{array}$ \\
\hline 6 & 10 & Female & Elazig & Liver HC & Liver cystotomy/cystectomy & 1/320 (+) & E.g. sensu stricto & $\begin{array}{l}\text { Hygiene conditions (poor) } \\
\text { Contact with dog (No) }\end{array}$ \\
\hline 7 & 5 & Male & Elazig & Liver HC & Liver cystotomy/cystectomy & $1 / 160(+)$ & E.g. sensu stricto & $\begin{array}{l}\text { Hygiene conditions (poor) } \\
\text { Contact with dog (Yes) }\end{array}$ \\
\hline 8 & 3 & Male & Mus & Liver HC & Liver cystotomy/cystectomy & $1 / 160(+)$ & E.g. sensu stricto & $\begin{array}{l}\text { Hygiene conditions (poor) } \\
\text { Contact with dog (Yes) }\end{array}$ \\
\hline 9 & 13 & Male & Diyarbakir & Liver HC & Liver cystotomy/cystectomy & $1 / 320(+)$ & E.g. sensu stricto & $\begin{array}{l}\text { Hygiene conditions (poor) } \\
\text { Contact with dog (No) }\end{array}$ \\
\hline 10 & 14 & Female & Mus & Liver HC & $\begin{array}{l}\text { Liver cystotomy/cystectomy/ } \\
\text { Nasobilier stent+sphincterotomy }\end{array}$ & $1 / 320(+)$ & E.g. sensu stricto & $\begin{array}{l}\text { Hygiene conditions (poor) } \\
\text { Contact with dog (Yes) }\end{array}$ \\
\hline
\end{tabular}

the possible risk factors related to CE patients, a thourough history concerning the sanitary conditions in house, the contact with dogs and the conformation to the general rules of hygiene was taken.

For the purpose of molecular characterization, cyst material was collected during surgery and fixed in 70\% ethanol until use. Genomic DNA was extracted from cyst walls (germinal layers) using a commercially available DNA extraction kit (MBI Fermentas, Lithuania) following the manufacturer's instructions. Prior to extraction, cut tissues were washed with PBS for at least 5 times. E.g.ss 1. for ( $5^{\prime}$-GTATTTTGTAAAGT TGTTCTA-3') and E.g.ss1.rev (5'-CTAAATCACATCATCTTACAAT-3') primer pair was used to amplify a fragment of the mt-12S rRNA of E. gramulosus sensu stricto (10). PCR reaction was carried out in a final volume of $50 \mu \mathrm{l}$, containing $5 \mu \mathrm{l} 10 \times$ PCR buffer, $5 \mu \mathrm{l} 25 \mathrm{mM} \mathrm{MgCl}_{2}, 250 \mu \mathrm{M}$ each of dNTP, 20 pmol of each primer, 200 ng of template DNA, and 1.25 IU of Taq DNA polymerase (MBI Fermentas). The PCR products were separated on agarose gels (1.4\%) and stained with ethidium bromide.

Hydatid cysts removed surgically from 10 pediatric patients residing in different provinces of eastern Turkey were included in this study. The demographic characteristics and some risk factors of these CE patients are given in Table 1. Molecular analysis of all the cysts obtained post operatively, showed the presence of PCR bands and thus patients were confirmed of CE.

The patients consisted of 7 (70\%) boys and 3 (30\%) girls (Table 1). Eight (80\%) patients had associated with only liver hydatid cyst while 1 patient had liver and lung hydatid cyst and the other liver, lung and spleen, together. Two (20\%) patients had associated with ruptured liver cysts. CT scan confirmed the diagnosis in all patients. Although all cases have been found positive before surgery by serologically between $1 / 160$ and 1/320 titers, during the follow-up, no increase was observed in hemagglutination levels and there were no mortalities and no evidence of recurrence in all patients after 2 years from surgery. All of them received oral Albendazol after surgery during 6 months.

Evaluation of the questionnaire forms given out to the children's parents for the evaluation of some risk factors, 7 cases with CE (70\%) were found to have a contact with dog and all patients were living under poor hygiene conditions.

A total of 10 hydatid cyst samples (germinal/laminar layer) were tested for the molecular analysis. All these samples were analyzed using $12 \mathrm{~S}$ rRNA primers. The $12 \mathrm{~S}$ rRNA PCR with the E.g.ss1for. and E.g.ss1rev. primers yielded 254 bp of amplification product in all samples analyzed. These samples were identified as the G1/G3 cluster of E. granulosus sensu stricto.

Cystic echinococcosis is an endemic zoonosis in many parts 
of Turkey and is a cause of serious outcomes due to morbidity in humans and considerable economic loss in livestock. Socioeconomical, agricultural, educational, and environmental factors contribute to the transmission of infection especially in young individuals. Besides, lack of education about the life cycle of the parasite contributes to transmission of this disease (5). CE is considered a rural disease because of the characteristics of the parasite life cycle which requires domestic mammals (11). Similarly, in this study, all the patients live in rural areas. Close contact with dogs was confirmed for 7 patients while all of them lived under poor hygiene conditions.

The most common location for hydatid cysts in children is the lung while adults mostly have hepatic cysts. Furthermore, combined liver and lung cysts are more frequent in children than in adults. Some other studies assume that high elasticity and compressible tissue of lungs in children leads to a faster grow of hydatid cysts in lungs than the liver (10-13). On the contrary, results of our study showed that the liver is a more frequently affected organ than the lungs.

Liver hydatid cysts may improve slower than lung cysts because of the less elasticity of the lung (14). This may explain the lower incidence of hydatid cysts in the liver. It was reported that hydatid cysts in the lung and liver had nearly equal incidences (41-43\%) in pediatric patients (15). On the other hand, the average ratio of liver/lung infections was reported as 1.25. In the same record, the lung cysts were seen in the 12-14 years old group whereas in the 6-8 year-old and 9-11 year-old groups, the liver cysts were detected (16). However, in our study, cysts were seen most commonly in the right liver lobe (70\%) and less in the left liver lobe (30\%).

Concerning treatment of $\mathrm{CE}$, this study showed that surgery was the chosen treatment method in pediatric cases. Although some surgeons prefer percutaneous-aspiration-injection and re-aspiration (PAIR) technique as the first line of treatment for liver hydatid cysts (17), it is contraindicated in a cyst communicating with the biliary tree. Thus, we used the surgical intervention in all pediatric cases in the current work.

Genotyping of human cases of CE play an important role in the formulation of control strategies for the prevention of transmission of this parasite. Strain variation in parasites exhibits variation in the onset of egg production, which is a limiting factor in control programs, which employs adult cysticidial treatment of the definitive host to break the cycle of transmission (18). Further, it is postulated that the strain variation in parasite may influence host specificity, life cycle patterns, development rate, transmission dynamics, antigenicity, and sensitivity to chemotherapeutic agents. Therefore, it may have implications for the development and design of vaccines and diagnostic reagents (3). This is the first detection of E. granulosus sensu stricto (G1-G3 strains) by molecular techniques in the eastern Turkey with regard to pediatric cases. These findings support to some previous reports where it was found hydatid cyst G1-G3 strains in cattle and sheep from this region $(7,19)$. We can conclude that common sheep strain may be more possible for the cause of pediatric cases due to the domestic cycle. Because the rate of relationship between children and sylvatic cycles of E. granulosus is lower than in adults. Because of the new and youngest cases in the study region, we can confirm that $\mathrm{CE}$ is still a public health concern in the rural area of estern Turkey. This situation shows that the continuity of the disease in the area depends on the natural transmission of the parasite, poor hygiene condition, contact with stray dogs, and absence of effective control and prevention measures.

The incidence of hydatid cyst increased by age in pediatric patients. The most effected organs were the liver and lungs. A conservative surgical technique is sufficient in most cases. Besides some risk factors such as poor hygiene condition, contact with dogs and uncontrolled livestock slaughtering should be considered, and people should be informed about these.

\section{CONFLICT OF INTEREST}

The authors declare that they do not have any conflict of interest.

\section{REFERENCES}

1. Thompson RCA. Biology and systematics of Echinococcus. In Thompson RCA, Lymbery AJ, eds, Echinococcus and hydatid disease. Wallingford, UK. CAB International. 1995, pp 1-50.

2. Grosso G, Gruttadauria S, Biondi A, Marventano S, Mistretta A. Worldwide epidemiology of liver hydatidosis including the Mediterranean area. World J Gastroenterol 2012; 18: 1425-1437.

3. Craig PS, McManus DP, Lightowlers MW, Chabalgoity JA, Garcia HH, Gavidia CM, Gilman RH, Gonzalez AE, Lorca M, Naquira C, Nieto A, Schantz PM. Prevention and control of cystic echinococcosis. Lancet Infect Dis 2007; 7: 385-394.

4. Bryan RT, Schantz PM. Echinococcosis (hydatid disease). J Am Vet Med Assoc 1989; 195: 1214-1217.

5. Bakal U, Kazez A, Akyol M, Kocakoc E, Simsek S. A portable ultrasound based screening study on the prevalence and risk fac- 
tors of Cystic Echinococcosis in primary school children in east Turkey. Acta Tropica 2012; 123: 91-95.

6. Šnábel V, Altintas N, D’Amelio S, Nakao M, Romig T, Yolasigmaz A, Gunes K, Turk M, Busi M, Hüttner M, Ševcová D, Ito A, Altintas N, Dubinský P. Cystic echinococcosis in Turkey: Genetic variability and first record of the pig strain (G7) in the country. Parasitol Res 2009; 105: 145-154.

7. Simsek S, Balkaya I, Ciftci AT, Utuk AE. Molecular discrimination of sheep and cattle isolates of Echinococcus granulosus by SSCP and conventional PCR in Turkey. Vet Parasitol 2011a; 178: 367-369.

8. Simsek S, Kaplan M, Ozercan IH. A comprehensive molecular survey of Echinococcus granulosus in formaline fixed paraffin embedded tissues in human isolates in Turkey. Parasitol Res 2011b; 109: 411-419.

9. Simsek S, Cevik A. First detection and molecular characterization of Echinococcus equinus in a mule in Turkey. Acta Parasitol 2014; 59: 773-777.

10. Dinkel A, Njoroge EM, Zimmermann A, Walz M, Zeyhle E, Elmahdi IE, Mackenstedt U, Romig T. A PCR system for detection of species and genotypes of the Echinococcus granulosus complex, with reference to the epidemiological situation in eastern Africa. Int J Parasitol 2004; 34: 645-653.

11. McManus DP, Zhang W, Li J, Bartley PB. Echinococcosis. Lancet 2003; 362: 1295-1304.

12. Mirshemirani A, Razavi S, Sadeghian S. Surgical treatment of pulmonary hydatid cyst in 72 children. Tanaffos 2009; 8: 56-61.

13. Santivanez S, Garcia HH. Pulmonary cystic echinococcosis. Curr
Opin Pulm Med 2010; 16: 257-61.

14. Aslanabadi S, Zarrintan S, Abdoli-Oskouei S, Salehpour F, Zarrintan A, Beheshtirouy, S, Abdollahi H, Badebarin D. Hydatid cyst in children: A 10-year experience from Iran. African J Paediatric Surg. 2013; 10: 140-144.

15. Montazeri V, Sokouti M, Rashidi HR. Comparison of pulmonary hydatid disease between children and adult. Tanaffos 2007; $6: 13$ 18.

16. Talaiezadeh A, Maraghi S. Hydatid disease in children: A different pattern than adults. Pakistan J Med Sci 2006; 22: 329-332.

17. Dopchiz MC, Elissondo MC, Andresiuk MV, Maiorini E, Gutierrez AM, Muzulin PM, Rosenzvit MC, Lavallen CM, Denegri G. Pediatric hydatidosis in the south-east of the Buenos Aires province, Argentina. Rev Arg Microbiol 2009; 41: 105-111

18. Giorgio A, Di Sarno A, de Stefano G, Liorre G, Farella N, Scognamiglio U, Giorgio V. Sonography and clinical outcome of viable hydatid liver cysts treated with double percutaneous aspiration and ethanol injection as first-line therapy: efficacy and longterm follow-up. AJR Am J Roentgenol 2009; 193: W186-192.

19. Thompson RCA, McManus DP. Aetiology: parasites and life-cycles. In: WHOO/OIE Manual on Echinococcosis in Humans and Animals: A Public Health Problem of Global Concern (Eckert J, Gemmell M, Meslin F-X, Pawlowski Z eds.) Paris: World Organization for Animal Health. 2001, pp 1-19.

20. Utuk AE, Simsek S, Koroglu E, McManus DP. Molecular genetic characterization of different isolates of Echinococcus granulosus in east and southeast regions of Turkey. Acta Trop 2008; 107: 192194. 